\title{
Lived experiences of undergraduate Physical Education students studying gymnastics and dance education
}

\author{
Gavin Ward \\ Institute of Sport and Human Sciences, University of Wolverhampton, United Kingdom \\ Gavin.Ward@wlv.ac.uk \\ David Scott \\ Institute of Education, University of Wolverhampton, United Kingdom
}

\begin{abstract}
The focus of this study was to understand undergraduate students' experiences of gymnastics and dance education within the scrutiny of modular learning in Higher Education. A phenomenological position was adopted in order to understand the wholeness of students' experiences whereby identities are constituted through their lived lives. This allowed us to understand the students' identities as relational to the learning and assessment context and their lives within and beyond university. Open-ended interviews were conducted with a purposive sample of students who consented to share their experiences. Data was analysed using Merleau-Ponty's theorising of identity as an embodied cohesion or habit between prepersonal and personal existence. This is revealed through opaqueness and transparencies of consciousness which in this study were revealed through the seven identities of the participants; Negotiating and surviving White space, Strategic masculine competitor, Seeking reassurance, Racially strategic to be unique, Seeking dependence to achieve, Strategically insular and Willing explorer. These identities help to shed light on the tensions Higher Education students may experience when confronted with new learning situations in which they are to be assessed. We concluded that getting to know students, and the opacities and transparencies of their identities, could be of great value in shaping their be-ing as students. In striving to understand the habitual behaviours of students, it is possible to understand how the subject-matter being taught might be received by students within the wider context of their be-ing-in-the-world.
\end{abstract}

Key words: Lived Experience, Phenomenology, Physical Education, Identity, Gymnastics, Dance

\section{Introduction}

There has been a growing body of work inspired by phenomenological positions which aim to understand the essences of experiences of sport and physical education (see e.g. Wessinger, 1994; Nilges, 2004; Ryba, 2007; Standal and Engelsrud, 2013; Allen-Collinson, 2014; Apelmo, 2018). These have been accompanied by a number of theoretical orientated publications which have shared the potential insights for both teachers and pupils of using phenomenological theories to understand learning in physical education (Thorburn, 2008; 
Brown, 2013; Stolz, 2013). Phenomenological positions have also aimed to understand more broadly how undergraduate students approach studying (Greasley and Ashworth, 2007) or their experiences of moving between student and professional identities (Secrest, Norwood and Keatley, 2003; Ferm, 2008; Wilson, 2014). Research reflecting undergraduate students' lived experiences of studying and being assessed in practical activities within physical education or sport is less prolific.

Modular courses at university level focus upon the development of specific subject knowledge, practical skills and professional experiences (Astin and Antonio, 2012). Within these structures student achievement is designated by the results of graded assessment tasks, which infer the learning of new knowledge. As a consequence, modular study at university level has developed into a space of significant scrutiny (Astin and Antonio, 2012). Marglois, Soldatenko, Acker and Gair (2001) remind us that beyond official declarations of module outcomes, assessments and lecture content, hidden curricula permeate interactions between teachers and students. Over forty years ago research started to identify the existence of these hidden curricula, where disconnections were revealed between the actions and decisions of students and the learning intentions of the modules (Portelli, 1993). Within the scrutiny of Higher Education assessment regimes, such studies have explored how students work strategically to enable them to maximise their success (Lynch, 1989). This line of research has also explored how particular norms and values permeate learning experiences, beyond official discourses, which can work to reproduce inequalities between race, gender and class (Jehangir 2010; Lynam and Cachia, 2018). How learning experiences within lectures and assessment preparation are enmeshed within students' wider lives is less well documented.

The focus of this study was to understand how undergraduate students live their experience of studying within the scrutiny of modular learning in Higher Education. The research grew from a number of impromptu, informal discussions one member of the research team had with his undergraduate physical education students. These conversations circled the students' personal experiences of their dance and gymnastics education modules. Such discussions were a catalyst for questions to emerge about the assumed pedagogical work of the modules and the reality of the students' personal experiences (Tinning, 2009). As a result of these questions, this study was conducted in order to try to understand the lived lives of these students in relation to their work within dance and gymnastics education. In wanting to understand the students' lived experiences, a phenomenological position was adopted in which the individual is the point of departure. From this monist position, the students' identities are constituted through their lived experience. This allowed us to understand the students' identities as relational to the context of studying gymnastics and dance in Higher Education. Open-ended interviews were conducted with a purposive sample of students who consented to share their experiences. This data was analysed by exploring each student's embodied experiences of the practical lectures and assessment tasks and how these experiences related to their present and historical lives within and beyond university. 


\section{Our Research Context}

The BA (Hons) Physical Education (non-qualified teacher status) course combines both practical and more traditional classroom based study of the subject. Two practical strands of study form the spine of the three year full-time degree course; one focuses upon pedagogical approaches, while the other aims to provide students with a pupil eye view of aesthetic activities. This is assumed by lecturers to be achieved through teaching the students gymnastics and dance as physical education subject-matter. Physical education is a historically gendered space in which activities such as gymnastics and dance are traditionally seen as activities for girls and women (Brown, 2005; Kirk, 2002; Scratton, 1993/2017). By aiming to expose the students to positive experiences within these activities, this strand of the course works to broaden students' conceptions of masculinities, femininities and challenge their understanding of what can be considered of 'value' within the subject. One member of the research team had taken a lead role in teaching and developing these modules which feature respectively in Year 1 and 2 of the course. This work was informed by his research interests in understanding knowledge as embodied experience. Cartesian mind-body dualisms commonly pervade conceptions of what it is to 'know' in physical education (Quennerstedt, Öhman and Öhman, 2011). In this way activities of the mind are separated and privileged over learning within practical activities (Crum, 1993; Thorburn, 2008). By assessing students' development and performance of dance and gymnastic compositions credibility is given to students' embodied understanding through the 'doing' of the activities. Balancing technical execution with creativity and exploration of movement creates a constant tension within the teaching of these modules.

The majority of students have a historical paucity in their physical educational experiences of dance and gymnastics. In view of these limited experiences and their narrow technical competence, the modules aim to explore and assess how complexity and challenge can be achieved. These concepts form the basis of the assessment tasks and the assessment criteria and aim to balance exploration and creativity with technical execution. Students are assessed via their performance of a dance and gymnastic composition. Complexity and challenge are illustrated, explored and assessed on the basis of how the students link together combinations of actions with movement elements such as levels, timings, directions, pathways and speeds, in addition to how different compositional devices such as canon, symmetry and mood, are interwoven. The quality and difficulty of particular actions, the technical aspects, form a part of the achievement of complexity and challenge. The modules aim to support students to 'think artistically' and to focus on creative processes and with a view to working towards a final performance piece (Eisner, 2003). In Year 1 the students work towards completing an aesthetic composition to music which is formally assessed. In this module the students are permitted to focus entirely on gymnastic actions or dance, or combine both mediums. In Year 2 they specialise in developing an assessed paired gymnastics sequences and an assessed dance performance in small groups.

The assumed pedagogical work of these modules is that they tackle some of the prejudices and limitations in the practices of physical education. To support their understanding, students are also required to analyse and grade the final performance of other 
students' work.. The assessment tasks and the teaching sessions aim to position the body as a place of experience rather than a site of psychomotor and physiological processes. Whilst the majority of students are reluctant at first to use their body to explore movement for its own sake, teaching staff aim to gradually build and reflect student's own work back to them, so they come to see themselves as dancers and gymnasts. In this way the aim is to develop a view of the body not as an object to be controlled by the mind but as a "subject in itself, deriving its subjectivity from itself" (Meier, 1988; p.91). This way of conceptualising the mind and body as being integral to each other and thus a means to understanding the world, was developed by the phenomenologist Merleau-Ponty. According to Thorburn (2008) embodied, monist approaches to understanding human experience have often been overlooked within physical education (cf. Stolz, 2013; Whitehead, Durden-Myers and Pot, 2018). By capitalising upon the removal of mind-body dualisms in articulating what it is to 'know' within physical education, Thorburn (2008) suggests new understandings of subjectmatter, learning and assessment can be developed (cf. Stolz, 2014).

\section{Adopting a Phenomenological position}

Monist ways of understanding experiences do not come without consequences. For example, Larsson and Quennerstedt (2012) suggest by foregrounding the body ahead of sociocultural influence, the work of race, gender and ethnicity upon bodies, and thus how the world is experienced, become overlooked. Phenomenologists, however, argue that it is by focussing upon the immediacy of experience that familiar assumptions about the world can be challenged (Nesti, 2004). By throwing suspicion on everyday experiences and culture, new understandings can be developed. According to Crotty (1998), phenomenology is a 'simple' concept in that it aims to return to 'things themselves' (p.78). As Connolly (1995) explains, investigating experience aims to establish a "renewed contact with the original experience" (p.26). Prior understandings of the world can pre-empt the meanings we derive from experience. By putting aside as best we can our cultural heritage, phenomenological researchers aim to understand how we make direct sense of the phenomena of our experiences. Phenomenology creates a position in which researchers strive to 'bracket off' these prior understandings and listen to experiences fully, as first hand, as they develop from our senses (Crotty, 1998).

Rather than viewing the body solely as a biological entity, Merleau-Ponty studied the intuitive experience of our bodily existence as part of its existence of 'being-in-the-world' (Kerry and Armour, 2000). In doing so, he developed a phenomenological position of 'lived space' in which experience is grounded in movement and language (Diprose, 2008). Such a position aimed to overcome mind/body and emotional/rational dichotomies by theorising our embodied position 'being-the-world' in which cognition is not privileged over our bodily experiences (Morley, 2001). Our lived body experiences do not become separated from cognitive learning, rather, knowledge is felt and sensed and not abstracted from experience. Merleau-Ponty's writings thus place the body as the subject of perception and the point of departure from which perceptions of the world are made and experienced (Stolz, 2013). From this position the world, body and consciousness are organically intertwined, phenomena are not separate, but feature as part of our embodied subjectivity or 'flesh-of-the- 
world' (Morley, 2001; p.75). Merleau-Ponty (1969) used the term 'intercorporeality' to capture this embodied positioning which includes both objects and other human bodies. Ongoing interactions of our flesh-of-the-world create a sensory dimension in which we both touch and are touched. Merleau-Ponty (1969) conceptualised this as reversibility where we both see, but also through situational reversal, are seen. The ongoing continuity of these interactions means our embodied subjectivity is both our seeing and being seen, touching and being touched. It is through this subjectivity that we derive meanings about our world.

\section{Phenomenological investigations of physical education}

Phenomenological positioning of embodied subjectivity has attracted a growing interest in writers who have observed how personalised meaning making through movement has become increasingly invisible within school physical education lessons. This shift in pedagogical focus to embodied subjectivity has primarily been employed to reconsider for example, the theorising of knowledge construction within physical education (Arnold, 1988), reconceptualisation of the subject as physical literacy (Whitehead, 1990), the justification of physical education (Stolz, 2013) and to inform reconceived curriculum and pedagogy (Brown and Payne, 2009). A search for phenomenological studies within peer reviewed journals that investigates physical education experiences of pupils suggests it is not a prolific area of research and studies often resides in unpublished thesis (cf. Bencal, 2003; Na, 2012, Rivard, 2015). Such research suggests that being 'good' and 'being seen to be good' come to the fore when participating in physical education (Wessinger, 1994; Nilges, 2004). These studies illustrate the complex architecture of relationships that lead to skillfulness and the role of the public gaze in generating feelings of joy and competence when studying physical education.

\section{Phenomenological studies of students' experiences of higher education}

Research which reveals students' explicit approaches to learning within physical education is less prolific within published research literature. This is partly because 'doing' rather than learning feature within the reported essences of experiencing the subject ( $\mathrm{Na}$, 2012). Phenomenological studies which capture the essences of students' experiences of studies of higher education are similarly less prolific within published research. Mullins and Preyde (2013) have explored the lived experiences of undergraduate students with an invisible disability. Their study describes the tensions between disabled students and university assessment cultures and how such students are required to constantly negotiate their status as validated learners. Greasley and Ashworth (2007) a phenomenological position to demonstrate the narrowness of psychometric approaches to recording students' studying habits. In doing so their study draws attention to very different meanings of what, on the surface, appear to be similar approaches to learning. In this way the individuality of the learner can be understood by the unique manner in which their approaches are interrelated with the context of their lifeworld.

A number of studies claiming to use interpretive phenomenological analysis exist which explore undergraduate nurses' experiences of giving and receiving care within medicalised institutions (e.g. Diekelmann, 1993; Porteous and Machin, 2017; Smith, Flowers and Larkin, 2009). Whilst these studies have aimed to capture the lived experiences of 
students through the claim of interpretive phenomenological analysis, what actually results is content or thematic analysis that does not draw explicitly from a phenomenological position (Allen-Collinson, 2009). According to Levering (2006) such studies gather data about the characteristics of concepts, rather than moving beyond everyday language, personal prejudices and scientific concepts in order to capture the embodied wholeness of lived lives. In aiming to avoid such pitfalls, Ferm (2008) for example, explores embodiment and identity in music teacher education to reveal how personal experiences and learning goals become focal points of tension in the development of trainee teachers' identities. From this phenomenological perspective, identity is considered to be constituted in the interrelations between the world and other human beings. Ferm (2008) thus demonstrates how trainee teachers can evolve yet maintain a stable identity in a continual process of reinterpreting their personal histories and considering their future selves. In this way our personal past does not just become history that remains the same, rather is subject to change.

According to Levering (2006) we carry with us our past, but this past will change as we change and re-interpret it in relation to our present and future. Levering (2006; p.461) argues "self-perception is interpretation and identity is self-interpretation", as such our personal histories are not unchangeable data but situated within a process of personal interpretation and re-interpretation (Levering, 2006; p. 461). Human beings and the world are intertwined in the process of intentionality; how we are directed towards the context we are within and the meaning this consequently generates. According to Ferm (2008) it is within this process that identity develops, and thus becomes relational.

\section{Theorising Identity within Lived Experience}

Exploring the self-narratives of students within their lived experiences of sporting activities, where the body is a key site for learning, brings to the fore fundamental questions about the relationship between mind-body. Such questions reveal two opposing historical views about how we explain human action. At one end are situated mechanical, cause and effect explanations which tend to prevail in empiricist accounts. At the other end, and in direct contrast to such explanations, are intellectualist accounts where bodily movements are controlled by the mind (Baz, 2017). Philosophers have aimed to dissolve these mind-body dualisms by positioning knowledge and learning within a dialectic relationship between the environment, body and mind (Quay, 2014). Different positions structure and position the dialectic in different ways in order to avoid resorting to favour either an intellectual or empiricist account (Antich, 2018; Baz, 2017). At the other end, empiricism tends to explore the cause and effect explanation of action within the role of personal experience. Intellectualism on the other hand, while bringing personal level accounts into action, subordinates control of the body to favour activities of the mind (Antich, 2018; Baz, 2017). As an existentialist philosopher, Merleau-Ponty (2012) was interested in theorising a position which aimed to capture human agency within the wholeness of experience. As a result he established the body as an integral part of experience and theorised it within an enmeshed relationship of ideas and memory (Diprose, 2008). In doing so, our physicality becomes a simultaneous way of be-ing-in-the-world. This term is hyphenated to capture the ongoing integral positioning of the self within the world. Merleau-Ponty (2012) conceptualises this 
be-ing as 'embodied freedom' in which we are neither fully free nor completely determined, and never separate or defined by our lived context (Carman, 2008).

From this existential position the challenge for the individual is to live an authentic life (Nesti, 2004). This life may never fully be realised, but the concept attempts to encapsulate the agency and resultant anxiety involved in making decisions and choices without certainty of outcome (Antich, 2018). Feelings of frustration, regret and despair result from ignoring our agency and abandoning the need to take responsibility in choosing our own course of action (Nesti, 2004). According to Antich (2018) this creates difficulty in understanding the way in which self-narrative functions to shape the self, and in particular, its potentially deterministic role in constituting the self. Antich (2018) suggests MerleauPonty's theorising of pre-personal and personal existence enables us to understand the role of pre-personal cohesion of identity in constituting the self through self-narrative. McGuirk (2014) explains such an account enables the past, others and nature to play their role in the development of the self, but importantly this development does not foreclose the future as a future of sameness. Instead, our personal history becomes part of our capacity to move into a future as a new space of possibilities. This is made possible by Merleau-Ponty's understanding of habits. According to McGuirk (2014), be-ing-in-the-world is constituted through mental social, cultural and physical habitualities as corporeal actions. He argues "to be an ego is to be an habitual ego, an ego of capacities" (p.153); it is these habits which constitute a personalised style of making sense of, and living-in-the-world. RomdenhRomluc (2015) suggests whilst Merleau-Ponty uses the term habits, he actually conceptualises what we understand are 'skills' because they are not static ways of being, rather are dynamic dispositions through which we are able to be imaginative, creative and spontaneous.

\section{The role of Habits within the negotiation of Identity}

According to Antich (2018) Merleau-Ponty constitutes habits as the dialectic between a personal self and a pre-personal self. He describes the personal self as the phenomenological self, one that is conscious of objects and selects objectives. Lying beneath this personal self is a pre-personal self which both challenges and enables the personal self to develop a self-narrative. Antich (2018) reminds us these selves are corporeal, therefore, beneath our personal experience of our body, is our habitual body which mediates our relationship within the world, without always drawing direct attention. A margin of 'almost' impersonal existence surrounds our personal existence (Merleau-Ponty, 2012; p.86). This pre-personal habitual body can be aligned or exist in conflict. For example, an initial university practical dance lecture can create alignment or conflict between pre-personal and personal narratives for different students. For the novice dancer their pre-personal habitual body may conflict with the personal experience of being required to be fluid, graceful and expressive. It is within this dialectic between pre and personal self that identity emerges. This novice dancer, in the challenge between the pre-personal and personal may, for example, reject this personal need to move differently but may still value dance as a part of physical education curricula. 
According to Merleau-Ponty (2012) pre-personal existence functions to challenge personal existence by distracting it beyond the meaningful to present a new future:

"...my possession of my own time is always deferred until the moment when I fully understand myself, but that moment can never arrive ... . My voluntary and rational life thus knows itself to be entangled with another power that prevents it from being completed and that always gives it the air of a work in progress. Natural time is always there. ... I am never at one with myself' (p. 363).

Our past does not pre-determine our present and future, rather the temporal quality of be-ingin-the-world, creates an incomplete personal narrative. This remains incomplete because experience of the past may be recast into new meaning by present experiences and recast again by future events (Antich, 2018). For example, a trained gymnast who is used to being given sequences by their coach to perform for competition, may be challenged by university teaching which requires them to be creative and work beyond traditional structures of gymnastic sequence construction. Within this challenge the gymnast may recast their prepersonal habits as limited ways of engaging with gymnastic movement. This new understanding, however, may then be recast in the future when they teach in a school in which formalised, traditional gymnastic sequences are expected and highly valued. Prepersonal existence thus both challenges and creates personal existence.

Dreyfus (2005) has developed Merleau-Ponty's view of habits by positioning motor skills at their heart, and argues that skills produce a state of 'flow' (Csikszentmihalyi, 1990), where the player is not explicitly thinking about the actions but the context in which they are being used. Using this position, Romdenh-Romluc (2015) suggests Merleau-Ponty actually describes habits as skills and thus his position on agency does not resort to empiricist views. However, in suggesting that habits are equitable to skilled behaviour, Romdenh-Romluc (2015) warns that it could be argued that an intellectualist position becomes apparent because skilled behaviour can be guided by thought. Using the work of Ricoeur (1966) and Ravisson (2008), McGuirk (2014) illustrates how this position is avoided by considering how habits interact with consciousness. Using the work of Ricoeur (1966), McGuirk (2014; p.156) illustrates how thinking can interrupt the flow of skillfulness and thus how habituation allows the subject to slip away from itself, where thinking becomes partially 'opaque' of explicit consciousness and creates the space for spontaneity. Habits operate out of the ground, which may have receded from view and become less apparent in our perceptions, of seeing, understanding and acting (Ricoer, 1984, 1992 and Ravaisson, 2008 cited by McGuirk, 2014). Accordingly, McGuirk (2014) suggests it is this ground which forms the basis for perception. Opacities do not prefigure thought and are not controlled by thought rather, they are the way in which the self becomes a single knower (McGuirk, 2014). Identity is thus embodied within the tension between full transparencies and blind opacity (McGuirk, 2014). For example, an experienced competitive gymnast who has been trained to copy competitive routines will move within this tension. When tasked to create their own routines using particular compositional structures, opacities will allow the gymnast to be able to work with some flow within this task. When transparencies appear their pre-self may challenge their immediate experiences and thus they will tussle with what is required of them. 


\section{Purposes, Aims and Research Questions}

The purpose of this study was to explore student's lived experiences of gymnastics and dance within an undergraduate Physical Education degree. In doing so it aimed to understand their lived identities as relational to their interpretation and reinterpretation of their personal histories. Of particular interest was the exploration of the presence of opacities and transparencies which emerged from the students' habits within the context of their participation in modules of dance and gymnastics education. The research question which drove this study was; what is the lived experience of be-ing a physical education student while studying undergraduate gymnastics and dance?

\section{Methods}

In order to address this research question we strove to adopt a phenomenological attitude throughout the data collection and its analysis (Kerry and Armour, 2000; AllenCollinson, 2009). In adopting this attitude, the researchers were attentive to participants' experiences of phenomena and aimed to ensure it foregrounded all elements of the research processes. As such, "the phenomenological method is the phenomenological approach itself" (Kerry and Armour, 2000; p. 8). While a prescriptive set of methodological tools in how to do phenomenological research would be antithetical to the foundational philosophy of phenomenology itself, detailed accounts do exist of what might constitute good practice in phenomenological exploration. Such accounts include a need to focus upon essences, description, epochē and intentionality (Allen-Collinson, 2011), utilising open-ended interviews to garner rich descriptions (Nesti, 2004), and being explicit in which school of phenomenology aligns most closely to the researchers' own philosophies (Cohen and Omery, 1994). In this latter regard we identified with Merleau-Ponty's (2012) theorising of the lived body as a point of departure to understand student experiences and thus their lived identities. In using such a position we followed a well-trodden path of pursuing phenomenological inquiry into the experiences of those who have not traditionally been heard (Levering, 2006). We thus took a methodological "risk" (Levering, 2006) in seeking students' emotive and personal perspectives to help uncover their unknown lived lives, in order to aid both lecturers and students to enhance future teaching, learning and assessment experiences.

Seven students consented to be involved, two of whom were in their first year and five of whom in their second year of their BA(Hons) Physical Education course. Ethical clearance was obtained from a university ethics committee and data was subjected to rigorous management in line with new general data protection regulations (British Educational Research Association, 2018). Each student was interviewed separately for between 30 and 70 minutes at the end of a semester during which all had completed a module of dance and gymnastics, during which a phenomenological attitude was consistently sought through the loosely structured, open-ended and participant led nature of our interview technique (Kerry and Armour, 2000). This involved asking a similar opening question to each participant of "how did you feel about the dance and gymnastics module?", before asking follow up questions based on their responses. However, there were common themes which each 
participant discussed, which included their experiences of the module content, assessment of the module, working with fellow students during the module, familial influences, past engagements with dance and gymnastics, and future career aspirations.

In consenting to be interviewed and willingly answering the questions posed, the students were co-opted by the research team into explicitly reflecting upon their habitualities and the interpretation and reinterpretation of their past and present selves. In effect we acknowledged our role in encouraging the students to engage in these reflections which they may not have done otherwise. After conducting the first three interviews it was clear the participants engaged more with the member of the research team who had taken a lead role in the teaching of the modules, which was contrary to an imbalance in power which can typically occur in such situations (Kvale, 2006). We theorised that the students had already established a connection and semblance of rapport with the lecturer, as both parties had encountered the environment and tasks pertaining to the topic of discussion. As a result it was possible that "I-thou" encounters (Buber, 1958) had been created whereby the interviewer was able to embody empathetic understanding through their shared experiences. Whilst the other member of the research team also strove to foster these interview conditions, and still gained rich data worthy of inclusion in the analysis, it was clear that there were less apparent shared biographies between this interviewer and the participant (Allen-Collinson and Owton, 2014). On this basis it was decided that the students' lecturer should conduct the remaining interviews in order to facilitate richer accounts of the participants' experiences.

Transcripts of the interviews were analysed using Dale's (1996) description of phenomenological analysis. Our analysis involved immersion into the data by both researchers listening separately and together to each audio recording several times, noting down our initial reflections and developing meaning units. These were constructed around the relations between each student's narrative as a whole, their habits within this narrative and the emergence of opacities and transparencies in the narration of these habits. These meaning units were cross referenced between each student and then worked up into larger clusters in order identify the essence of their habits and thus their lived identity as lived experience within gymnastics and dance.

\section{Findings}

It was surprising that the students made very little explicit reference to their bodies within the context of dancing and doing gymnastic moves. Rather the students talked about how they negotiated the challenge of doing unfamiliar activities or activities in which they had not participated since primary and/or secondary school. Each student reported the pervading gaze of lecturers, other students and the final assessment tasks. This seeing and being seen was imbued with gendered and racialised lenses within which were woven perceptions of what constituted quality work.

As they narrated and reflected upon their past and current biographies of doing dance and gymnastics, their particular way of living the modules came to the fore. These identities were implicit to their previous experiences, the challenges they faced in the modules and the 
contexts in which they worked to construct their assessment compositions. As the students described, narrated and reflected, tensions between past and present selves were the means by which the characteristics of these identities developed their form. The architecture of these identities emerged in the opacity and transparency of the tensions between their past and present selves. For example, transparency between their past and present selves was reflected in the manner in which they were conflicted in their work in dance and gymnastics. In was here that frictions between habitual ways of working and present contexts were identified and new possibilities were drawn. Opacity was apparent when the students were less conscious of how their established habits and casting of past experiences foreclosed possibilities for them within the modules.

To illustrate the individual variations in the architecture of the students' identities we use a 'castle', 'drawbridge' and 'villagers' metaphor which portrayed the "fundamental structure of the data" (Dale, 1996, p. 315). A castle is employed to represent each student's particular way of seeing the world. A drawbridge is used to represent the ways students negotiated the scrutinised space of gymnastic and dance. In using this drawbridge the students interacted with the villagers, which represent the lecturers and other students. Each of the seven students' castles, drawbridges and interactions with villagers, constituted a way of living the gymnastics and dance lectures and these are represented in the following characterisations:

- $\quad$ Negotiating and surviving White space

- Strategic masculine competitor

- $\quad$ Seeking reassurance

- $\quad$ Racially strategic to be unique

- Seeking dependence to achieve

- $\quad$ Strategically insular

- Willing explorer

\section{Negotiating and surviving White space}

Hamed had previously attended a secondary school in which Asian students were in a significant majority, whereas now at university he was in a space in which he felt he was a racial minority. This distinctness in difference characterised a perceived gulf between the familial cultural expectations which Hamed believed were placed upon him and other Asian students, but not the other White students in his course group. The stones of his castle were characterised by significant expectations in relation the need to obtain a career in a respectable profession with a correspondingly respectful remuneration. These expectations served to develop his credentials as a desirable, prospective husband, homeowner and father, which he felt had to materialise in relative succession once he graduated. Hamed's castle formed a highly gendered, delineated space of values which served to influence what constituted manly and credible educational activities. He described himself and fellow Asian students as being at a distinct disadvantage because "everyone could do it except us". For Hamed, the "others, White students, experienced gymnastics and dance at school", where as he and his fellow Asian students were limited to games such as cricket and football. He saw gymnastics as an activity that was about "making masculinity look attractive and feminine" and which you either "know it or not". Having to dance and move gymnastically 
significantly challenged Hamed's masculinity and challenged his parent's values of what constituted degree level educational activity. Negotiating this challenging landscape demanded a robust drawbridge. Hammed's was constructed from his avoidance of the shame of "dropping out" and the damage this would bring to his credentials as a prospective, respectable professional. This structure was reinforced by his skill at negotiating the clash between his familial and cultural values that would lead to potential shame and ridicule if he was to disclose that he did dance and gymnastics. Hamed claimed to be "learning to teach" when doing practical lectures and regularly took home books so it looked like he was "doing some real academic work". He said he would wait until he graduated before disclosing what he "actually did" on his degree to his family. This subversive negotiation led him to become part of a survival group of villagers that comprised other Asian students who Hamed stated shared his conflicted world. In this way Hamed constantly negotiated to survive White space.

\section{Strategic masculine competitor}

Tyrone's castle was constructed out of competitive engagement with his brothers, friends and participation in sport cultures at school. Thick veins of a desire to be seen as masculine and to be somewhere on a ranked scale of worth, ran throughout the stones of his castle. Although used to having to "measure up" and act "manly" at home, Tyrone found gymnastics and dance challenging activities in which to compete. Without having much experience in gymnastics and only dancing in private as a "guilty pleasure", his drawbridge was fashioned from being competitive and by positioning lectures as a means to train for the assessment. All women were blanketly labelled by Tyrone as experts in gymnastics and dance as they were "freer and able to express themselves" and had "flexibility and gracefulness". Such presumptions precluded him from seeking a female partner because "they would be better and have one up on me", thus making him appear a less credible team member and competitor. This reflected how Tyrone interacted with other villagers, using them as a gauge to see how he was measuring up and whether he was "getting it right or not".

All the time this had to be done whilst maintaining his sense of masculinity. Tyrone felt particularly confident when doing the flight lectures in gymnastics as it was more "dangerous and competitive", particularly, when he looked around and saw himself as being "up there with most of the good guys". Recalling a mistake in choosing a "weaker partner" in his first year, Tyrone actively sought a fellow male who he could compete with, in order to do better in his second year. This characterised Tyrone's gendered strategic competitiveness.

\section{Seeking reassurance}

Georgina had participated and competed in Ice Dance since an early age. She continued to dance with her male partner and female coach but only to "keep active and stay fit". Although having this background and some experience of gymnastics at primary school, Georgina struggled with the freedom and challenge of creating a dance performance. Her castle was constructed from being trained to be compliant and to do what she was required to do by her coach and dance partner. This included completing the moves she was told to do. Georgina believed this regime helped her to "express" herself more freely than she was able to do in the lectures. The open creative space of needing to develop personal ideas to express 
in dance thus proved bewildering. Georgina took the videos of her dance to show to her mum and sister so they could help and practice with her. Her drawbridge was thus formed out of her understanding of the need to check and receive reassurance that what she was doing " $O K$ ". Georgina's choice of villagers reflected her historical experience of ice dance, by choosing a male partner the same age as her. She often turned up with some volition to develop a quality piece of work but unfortunately her partner turned out not to be "too bothered with trying too hard as it was only a first year assessment, so he just wanted to pass". Georgina thus returned home to practice in a place of positive, non-threating scrutiny where she felt she could be more "relaxed and expressive" and receive the reassurance she sought.

\section{Racially strategic to be unique}

Shaqiem actively sought to be seen as "different from everyone else" and not a "typical British Asian Pakistani". Gymnastics and dance created a space in which he could continue to aspire to this desired identity. His castle was formed of masculine blocks of stone and that represented his continual quest not to be type-cast and to able to move between White and brown cultural values. In dance Shaqiem deliberately choose to work with a White female and in gymnastics a White male, who were part of his circle of friends. He rejected the other Asian men because he did not want to be "identified with those guys because I wanted to be more sociable". Shaqiem aimed to impress the females in the group by showing he could be "out there and loud and standing out". He used this strategy as a way he could gauge the maintenance of his masculinity by seeing if the females continued to engage in a positive way with him. In this way Shaqiem was able to manage a manly persona which included expressive athleticism. His drawbridge was constituted through his desire to obtain educational capital, which would be unique to his old school friends, community peers and family. This enabled him to seek out female villagers whom he perceived were "slim and fit" and who had already demonstrated that they had some expertise. Shaqiem believed it was his energy and readiness to prove to the White females and males he could "do dance and gym". Whilst this strategy works for obtaining a female partner in dance that lead to a "really good grade, way better than I thought I would get", in gymnastics he did not do so well when he partnered a man for gymnastics. Shaqiem sought a strong man because this would be needed to deliver a quality gymnastics composition composed of "tough partner balances and lifts". Contrary to his strategic work in dance, this plan did not work as his gymnastic grade was substantially lower. Shaqiem reflected that this was a result of a disconnection between their preconceived ideas of what constituted a quality gymnastics sequence compared to that described in the assessment process.

\section{Seeking dependence to achieve}

Emily used to play golf competitively from an early age, which demanded a tough regime of practicing and preparation for tournaments. As a consequence she relied heavily on family and a long term personal coach. The unexpected "shocked......... bereft loss of my coach" who had "seen me through years and years of developing my game" and an issue with a personal long-term relationship were marked experiences for Emily. Her degree studies represented a new space to experience more secure and less controlling relationships. To 
succeed on the degree, Emily believed she needed to choose "the right partner" and had teamed up in Year 1 with Abbie who she viewed as a capable peer. To prove her creditability to Abbie, Emily reported working "to show I am a worthy partner". She was "devastated" that Abbie was injured and could not do the assessment in Year 2. However, she, a friend and Abbie, used their prior knowledge of the males through lectures to "trial which lads may be worth teaming up with". This was couched in a belief that male-female pairs scored higher grades. Emily often doubted herself, "freaked-out when we did flight" and "froze when I had to come up with movement ideas on my own". Abbie proved a key ally in the lectures and served to provide a source of ideas, direction and self-belief. This continued despite Abbie's injury through her presence at lectures and constant guidance and support. Emily's castle was founded upon her prior experiences with her golf coach, featuring blocks of stone that represented a palpable need for reassurance, support and continuity. This was juxtaposed with a drawbridge which was constituted from her perceptions of what it was to do well in dance and gymnastics. Emily's interactions with the villagers revolved around choosing peers and partners who would help provide her the necessary expertise, guidance and emotional stability to earn good grades.

\section{Strategically insular}

Golf continued to be Arthur's chosen sport, however, doing far less competitions and training than before university. He reported the many hours of practice and coaching, in addition to the relative isolation and need to be independent and confident when competing. Arthur had very limited prior experiences of dance and gymnastics and found the lectures daunting with new people, unfamiliar activities and assessments looming at the end. In Year 1 he formed a partnership with Daniel and chose to do dance because "there were less rules and it was easier than doing formal gymnastics moves". In this way "we felt we were freer to create work that would pass". In keeping with Daniel as his partner in Year 2, Arthur believed they were able to create a unit where they could develop their work relative to what they believed they were able to do. Arthur's castle was built from stones shaped by this selfassured desire to work within his own and Daniel's capabilities. His drawbridge was built from an ethical recognition that he may be obliged to teach gymnastics and dance as a Physical Education teacher and thus "should know something about them". Whilst he and Daniel participated in lectures he found some of the content irrelevant as he and Daniel were "not going to put most of that stuff" into their work. He would rather "have had more time practicing the things we wanted to do instead of doing quite a bit of the lectures". This involvement in the lectures characterised how he engaged with the villagers, limiting himself to his original partner who had seen him through Year 1. He choose to participate in lectures but only due to an ethical obligation and by working within his own and his partner's perceived capabilities Arthur characterised being a strategically dependent student.

\section{Willing explorer}

Usain originated from Jamaica and has revelled in the "fresh" identity the course was giving him, reflected in different interactions with work colleagues, church members and friends. In these engagements he was able to talk about the new insights and experiences he was developing, of which dance and gymnastics were a particular feature. The practical 
lectures provided an opportunity for him to think about himself and the physical changes in his body since leaving school and working. Despite being a musical family and playing an instrument himself, Usain's experience of dance was that of being "feminine and something the girls did". Being sporty on the other hand was different and although Usain recalled doing little gymnastics and dance at school in both the UK and Jamaica, he recalled the rough and ready athleticism of his primary schooling in Jamaica. Usain's castle was comprised of see-through bricks in which he was keen to engage with lectures and peers. The hard material of the glass was characterised by his gendered experiences of dance and a desire to do things in the "right way" and by having to learn what the rules of engagement were. To compliment an outward looking stance, Usain's drawbridge was constituted by a selfreflective stance and a desire to have new experiences and develop himself beyond his current employment. In engaging with lectures Usain was rediscovering and remembering what he used to be able to do and could potentially bring into his work. His interactions with the villagers was thus characterised by experimentation and reflection. In creating a gymnastics sequence he felt the structure and "rules were easier to follow and I could tell what was right". This differed significantly in dance when he realised through listening to feedback from staff, peers and his wife, that his composition was more acting and drama rather than dance. By acting on advice and being keen to rediscover and explore what he could potentially achieve in gymnastics and dance, Usain reflected that of a willing explorer.

\section{Discussion}

By consenting to be interviewed, the students were able to provide privileged insight into their lived worlds within and beyond university. This insight provided the opportunity to understand how opacity and transparency within their habitualities can both create and limit possibilities. For Hamed who reported his negotiating and surviving White space, we can see how his habit of working within racialised groups foreclosed seeing a different take on the dispositions and opportunities open to others. However, it is clear that the type of gymnastics defined by the assessment task was at odds with his be-ing and this point raises important questions about the potential for White privilege to be present in the forms of the gymnastics and dance defined in lectures and through the assessment tasks. Such questions cannot be treated lightly and this creates the impetus for further reflection and research into the racialised and gendered spaces of these modules. The consequences of opacity was clearly evident in Arthur's narrative in his habit of continuing to choose to work within his own conception of what he was able to do and how this reflected quality work. Reciprocity with his partner resulted in their strategic insulation from the anxiety and uncertainty and by avoiding their gymnastic actions from being scrutinised in Year 1. Tyrone's account also reflects opaqueness in his identity as a strategic masculine competitor. Whilst this allowed him to get on and attend to the need to pass and thus compete against others, it also foreclosed other possibilities. This unseeing meant he could not reconcile his pleasure with dance in private as a creditable and worthy engagement with dance. Similarly, his habitual competitiveness created a highly gendered view of who was able and what constituted quality dance work. In avoiding facing anxiety of not being as good as his partner, Tyrone foreclosed working with a woman who may have actually offered different possibilities in his dance and gymnastics composition. 
This foreclosure was similarly evident in Georgina's identity whereby she consistently sought reassurance to negotiate the challenges of being creative. There is a subtle transparency here where she was aware of the conflict between her biography of ice dancing and the need to develop and shape her own ideas of composition in her university work. This tension can be seen in her casting of her experience in ice dance as being expressive and creative. Such a narrow casting, couched in the need to make technical moves come alive, clashed with the assessment task that required her to be creative and adaptable in her construction of technical movements. Opaqueness clouded the possibility of reflection by foreclosing her present self by her choice to retreat from creating and developing her work in lectures with her partner. In doing so she sought the familiar company of her mum and coach who may actually be the harbingers of her conformity to less creative ways of working. Ironically, while she recalled her coach saying she could "do better than this", such assessment did not help to break down the opacity of her habit to reveal the narrow casting of her past self as creative and expressive. This also extended to her acceptance of a partner who was unwilling to take an equitable role in developing their composition.

Similarly strong habitualities were present in Shaqiem's use of using new settings as opportunities to subvert his race and to enhance his masculinity. Opaqueness was present as he used his past self to help his present self to negotiate a female dance partner. This was secured by using alignment of his masculinity with dancing to develop a rapport with chosen females. In reciprocating this rapport the targeted women helped him maintain his identity as an Asian man who could dance openly with White females. The opaqueness here led to Shaqem's over-security in his beliefs about what constituted quality work and who would help him to deliver a high grade in his gymnastics work. Transparency appeared when he was able to see how he had not paid sufficient attention to the gymnastics assessment task and had become clouded by his gendered view of quality gymnastics composition. Emily exhibited similarly strong habitualities in finding people to provide her with a her historical need for personal support. This support aimed to dissipate responsibility for her present self. Opaqueness here allowed her the space to invest and develop reciprocated supportive close partnerships. This was evidenced in her strategic moves to obtain a good grade despite Abbie, her personal coach and confidant being injured. She achieved this by trialling out boys as possible opportunities to obtain a higher grade which was closely supported by Abbie. In doing so transparency was also evident in how Emily recast her past self as victim, being dependent and controlled, to being more strategic in her approach. However, opaqueness remained in her continuity in relying on Abbie for approval and support.

To help him willingly explore, Usain similarly sought the support of others to help him reflect upon his journey of developing his identity. He was at ease with moving between transparency and opaqueness, and was open to the need to confront the anxiety created by being assessed in gymnastics and dance. He demonstrated active engagement with his past self to make sense of the challenges he faced by rediscovering his younger past athleticism. Usain used this casting of his past self to develop the opaqueness to tackle the assessment tasks. By actively exploring with others the meaning of quality within the context of the 
lectures and listening to feedback, he used his habit of reflecting to develop the transparency needed in order to grow his identity as a dancer and gymnast.

Taking the participants' experiences into consideration as a whole, the "inextricable intermixture" (Merleau-Ponty, 1962, p. 518) of freedom and determinism as experienced through embodied freedom was perhaps exacerbated by the academic context. The omnipresence of assessment seemed to pique the individuals' experiences of the dance and gymnastics modules. Despite the module, and hence assessment, claiming to foster expression and freedom of students' bodies, what is instead described by these participants is engagement with the hidden curricula of Higher Education (Marglois, et al., 2001). These actions within the learning space are brought into being by each participant's intentionality, whether they are discussed as a space of survival, such as by Hamed and Arthur, as a competition of masculinity and identity, as in the cases of Tyrone and Shaqiem, or through the dependence of support by others, as seen through Georgina, Usain, and Emily. In their own way each student is seeking for reconciliation between the anxiety experienced in their academic be-ing and the habits established in their personal be-ing, in an effort to experience as authentic a life as possible (Nesti, 2004).

It is also noteworthy that the reversibility of 'seeing and being seen' (Merleau-Ponty, 1969) did not necessarily occur between the student and their peers or lecturer. Rather, it was the reversibility of 'seeing and being seen' in the public domain of their learning, using their bodies to respond to teaching and to explore gymnastic and dance movement in order to produce work for their assessment. This led to a hyper-consciousness of the individual's use of their material body (Leder, 1990). As a result, the students questioned their own embodiment and embodiment of others, in terms of gender (e.g. wanting/not wanting to work with specific genders), race (e.g. defining dance and gymnastics as a 'White' space), and culture (e.g. hiding their participation in the module from others). Consequently, all the participants gave meaning to doing dance and gymnastics in a "right" or "wrong" way, which was not only in reference to the assessment criteria, but also in relation to their gender, race, culture, and life histories. Therefore, to a lesser or greater extent, students' embodied freedom (Merleau-Ponty, 1962) within their dance and gymnastics modules was strongly influenced, and in some cases regimented, by the opacities and transparencies of their present and prepresent selves.

This study helps to add to the growing body of research which is developing our understanding of lived experiences of learning in Higher Education. Mullins and Preyde (2013) revealed how students with an invisible disability laboured to legitimate themselves as validated learners. The students in this study similarly laboured to negotiate their past and present selves to legitimate their identities as dancers and gymnasts in relation to their gender, race and culture. The students in this study reflected how they worked to maintain a stable identity in a continual process of reinterpreting their personal histories and considering their future selves, in a similar manner to which Ferm (2008) discussed. Looking beyond the surface and understanding how students approach learning contexts has been explored by Greasley and Ashworth (2007) who suggested recognising the nuances of the individuality of 
the learner can help to tailor choices of pedagogical approach. In a similar understanding, students' negation of past and present self and their labour to find a legitimate identity may be an important consideration for both staff and students.

\section{Conclusions}

The varying opacities and transparencies of the participants' habits discussed in this paper has shed light on the tensions Higher Education students experience when confronted with new learning situations and associated assessments. For lecturers, this is a key finding which could influence how they develop their relationships with students. Getting to know the students, and the opacities and transparencies of their identities, could be of great value in shaping their be-ing as students. In striving to understand the habitual behaviours of students, it is possible to further understand how the subject-matter being taught might be received by students within the wider context of their be-ing-in-the-world. The consequences of this study point to additional questions to address. Firstly, there is an urgent need to explore the potential for White privilege in the construction of gymnastics and dance. Secondly, there is an opportunity to consider dialogue with the students in our interpretation of their identities and explore the outcomes of this dialogue with the intention of supporting their be-ing as students in Higher education.

The authors would like to thank the reviews for their closely considered evaluations and comments which have helped to develop and shape this research publication.

\section{References}

Allen-Collinson, J (2009). Sporting embodiment: sports studies and the (continuing) promise of phenomenology, Qualitative Research in Sport and Exercise, 1(3): 279-296

Allen-Collinson, J (2011) Intention and epoche in tension: Autophenomenography, bracketing and a novel approach to researching sporting embodiment, Qualitative Research in Sport, Exercise and Health, 3(1), 48-62.

Allen-Collinson, J. and Owton, H. (2014). Intense embodiment: Senses of heat in women's running and boxing, Body \& Society, Advance online publication. doi: 10.1177/1357034X14538849

Antich, P. (2018). Narrative and the Phenomenology of Personal Identity in Merleau-Ponty, Life Writing, 15(3), 431-445.

Apelmo, E. (2018). 'You do it in your own particular way' Physical education, gender and (dis)ability, Sport, Education and Society, doi:10.1080/13573322.2018.1452198

Astin, A. W. (2012). Assessment for excellence: The philosophy and practice of assessment and evaluation in higher education. Plymouth, UK: Rowman \& Littlefield Publishers.

Arnold, P. J. (1988). Education, movement and the curriculum a philosophic inquiry London: The Falmer Press.

Baz, A. (2017). The crisis of method in contemporary analytic philosophy. Oxford: Oxford University Press.

Bencal, C. (2003). Qualitative description of the physical education-based live exper4einces if non-aggressive socially isolated students (Unpublished Master of Arts dissertation), University of Maryland, USA, Retrieved from 
https://drum.lib.umd.edu/bitstream/handle/1903/183/dissertation.pdf?sequence=1\&isAllowed $=\mathrm{y}$

Brown, D. (2005) An economy of gendered practices? Learning to teach physical education from the perspective of Pierre Bourdieu's embodied sociology, Sport, Education and Society, 10(1), 3-23.

Brown, T. (2013). A vision lost? (Re) articulating an Arnoldian conception of education 'in' movement in physical education, Sport, Education and Society, 18(1), 21-37.

Brown, T. D. and Payne, P. G. (2009) Conceptualizing the phenomenology of movement in physical education: implications for pedagogical inquiry and development, Quest, 61(4), 418441.

British Educational Research Association (BERA) (2018). Ethical guidelines for educational research (fourth edition). London: BERA

Buber, M. (1958). The I-thou theme, contemporary psychotherapy and psychodrama, Pastoral Psychology, 9(5), 57-58.

Carman, T. (2008) Between empiricism and intellectualism (44-56). In R. Diprose and J. Reynolds (Eds) Merleau-Ponty: Key Concepts. Abingdon: Routledge.

Cohen, M. Z. and Omery, A. (1994). Schools of phenomenology (136-156). In J. M. Morse (Ed.),Critical issues in qualitative research. Thousand Oaks, CA: Sage.

Connolly, M. (1995). Phenomenology, physical education, and special populations, Human Studies, 18(1), 25-40.

Crum, B. J. (1993). Conventional thought and practice in physical education: Problems of teaching and implications for change. Quest, 45, 339-356.

Crotty, M. (1998). The foundations of social research: Meaning and perspective in the research process. St. Leonards, Australia: Allen and Unwin.

Csikszentmihalyi, M. (1990). Flow: the psychology of optimal performance. New York: Harper and Row

Dale, G. A. (1996). Existential phenomenology: Emphasizing the experience of the athlete in sport psychology research, The Sport Psychologist, 10(4), 307-321.

Diekelmann, N. L. (1993). Behavioral pedagogy: A Heideggerian hermeneutical analysis of the lived experiences of students and teachers in baccalaureate nursing education, Journal of Nursing Education, 32(6), 245-250.

Diprose, R. (2008) A guide to Merleau-Ponty: Key concepts (8-16). In R. Diprose and J. Reynolds (Eds) Merleau-Ponty: Key Concepts. Abingdon: Routledge.

Dreyfus, H. L. (2005). Overcoming the myth of the mental: How philosophers can profit from the phenomenology of everyday expertise. In Proceedings and addresses of the American Philosophical Association 79(2), 47-65.

Eisner, E. (2003) Imagination and the Arts, Language Arts, 80(5), 340-344.

Ferm, C. (2008). Playing to teach music-embodiment and identity-making in musikdidaktik. Music Education Research, 10(3), 361-372.

Greasley, K., and Ashworth, P. (2007). The phenomenology of 'approach to studying': The university student's studies within the lifeworld, British Educational Research Journal, 33(6), 819-843.

Jones, S. (2013). Perspectives of physical education from teachers, staff and students in a juvenile justice setting (Unpublished doctoral dissertation). The University of Alabama, 
USA, Retrieved from

http://acumen.lib.ua.edu/u0015/0000001/0001285/u0015_0000001_0001285.pdf

Kerry, D. S., and Armour, K. M. (2000). Sport sciences and the promise of phenomenology: Philosophy, method, and insight. Quest, 52(1), 1-17.

Kvale, S. (2006). Dominance through interviews and dialogues, Qualitative Inquiry, 12(3), 480-500.

Jehangir, R. (2010) Stories as knowledge: Bringing the lived experience of first-generation college students into the academy, Urban Education, 45(4) 533-553

Larsson, H., and Quennerstedt, M. (2012). Understanding movement: A sociocultural approach to exploring moving humans. Quest, 64(4), 283-298.

Leder, D. (1990). The absent body. Chicago: University of Chicago Press.

Levering, B. (2006). Epistemological issues in phenomenological research: How authoritative are people's accounts of their own perceptions? Journal of Philosophy of Education, 40(4), 451-462.

Lynam, S., and Cachia, M. (2018). Students' perceptions of the role of assessments at higher education, Assessment and Evaluation in Higher Education, 43(2), 223-234.

Lynch, K. (1989). The hidden curriculum: reproduction in education, a reappraisal. London: Falmer Press.

Marglois, E., Soldatenko, M., Acker, S. and Gair, M. (2001) Peekaboo: Hiding and outing the curriculum. In E. Margolis (Ed) The hidden curriculum in higher education (1-20). London: Routledge.

Meier, K.V. (1988) Embodiment, sport and meaning. In W.P. Morgan and K.V. Meier (Eds) Philosophical enquiry in sport (90-101). Champaign, IL: Human Kinetics

Merleau-Ponty, M. (1962) The phenomenology of perception (Translated by C. Smith). London: Routledge and Kegan and Paul.

Merleau-Ponty, M. (1969) The visible and the invisible. (translated by A. Lingis). Evanston, Ill: Northwestern University Press.

Merleau-Ponty, M. (2012) The phenomenology of perception. (translated by D. Landes). Abingdon: Routledge.

Morley, J. (2001) Inspiration and expiration: Yoga practice through Merleau-Ponty's phenomenology of the body. Philosophy East and West, 51 (1), 73-82.

Mullins, L., and Preyde, M. (2013). The lived experience of students with an invisible disability at a Canadian university, Disability and Society, 28(2), 147-160.

McGuirk, J. (2014). Phenomenological Considerations of Habit: Reason, Knowing and SelfPresence in Habitual Action, Phenomenology and Mind, (6), 112-121.

$\mathrm{Na}$, J. (2012). Students' and parents lived experiences in physical education and youth sport (Unpublished doctoral dissertation). The University of Georgia, Athens, USA, Retrieved from https://getd.libs.uga.edu/pdfs/na_jaekwon_201205_phd.pdf

Nesti, M. (2004). Existential psychology and sport: Theory and application. Abingdon: Routledge.

Nilges, L.M. (2004). Ice can look like glass: A phenomenological investigation of movement meaning in one fifth-grade class during a creative dance unit, Research Quarterly for Exercise and Sport, 75(3), 298-314. 
Portelli, J. P. (1993). Exposing the hidden curriculum, Journal of curriculum studies, 25(4), 343-358.

Porteous, D. J., and Machin, A. (2018). The lived experience of first year undergraduate student nurses: A hermeneutic phenomenological study, Nurse Education Today, 60, 56-61.

Quay, J. (2014). Education, experience and existence: Engaging Dewey, Peirce and Heidegger, Abingdon: Routledge.

Quennerstedt, M., Öhman, J., \& Öhman, M. (2011). Investigating learning in physical education - A transactional approach, Sport, Education and Society, 16, 159-177.

Rivard, L. (2015). Bringing forward Rwandan girls' perspectives on their lived experiences of physical activity and sport in secondary schools (Unpublished doctoral dissertation).

McGill University, Canada, Retrieved from

http://digitool.library.mcgill.ca/webclient/StreamGate?folder_id=0\&dvs=1542294948413 12 8

Romdenh-Romluc, K. (2015) Merleau-Ponty: Actions, habits and skilled expertise (89-116).

In D.O. Dahlstrom, A. Elipidoru and W. Hopp (Eds) Philosophy of Mind and Phenomenology. New York: Routledge

Ryba, T. V. (2007). Cartwheels on ice: A phenomenological exploration of children's enjoyment in competitive figure skating, Athletic Insight, 9, 58-73.

Scratton, S. (1993/2017) Equality, coeducation and physical education in secondary schools (139-153). In J.Evans (Ed.) Equality education and physical education. London: Routledge

Secrest, J. A., Norwood, B. R., and Keatley, V. M. (2003). " I was actually a nurse": The meaning of professionalism for baccalaureate nursing students, Journal of Nursing Education, 42(2), 77-82.

Smith, J. A., Flowers, P., and Larkin, M. (2009). Interpretive phenomenological analysis: theory, method and research. London: Sage.

Standal, O. and Engelsrud, G. (2013) Researching embodiment in movement contexts: A phenomenological approach, Sport, Education and Society, (18)2, 1357-3322.

Stolz, S. (2013). Phenomenology and physical education, Educational Philosophy and Theory, 45(9), 949-962.

Stolz, S. (2014) The Philosophy of Physical Education: A New Perspective. Abingdon: Routledge.

Thorburn, M. (2008). Articulating a Merleau-Pontian phenomenology of physical education: The quest for active student engagement and authentic assessment in high-stakes examination awards, European Physical Education Review, 14(2), 263-280.

Tinning, R. (2010). Pedagogy and Human Movement: Theory, Practice, Research. Abingdon: Routledge

Wessinger, N.P. (1994) "I Hit a Home Run!" The lived meaning of scoring in games in physical education, Quest, 46, 425-439.

Whitehead, M. E. (1990). Meaningful existence, embodiment, and physical education, Journal of Philosophy of Education, 24(1), 313.

Whitehead, M. Durden-Myers, E and Pot, N. (2018). The Value of Fostering Physical Literacy, Journal of Teaching in Physical Education, 37(3), 252-261.

Wilson, A. (2014). Being a practitioner: an application of Heidegger's phenomenology, Nurse Researcher, 21(6), 28-33. 
